Int. J. Electrochem. Sci., 13 (2018) 10973 - 10989

\title{
Flubendazole: New Corrosion Inhibitor for 6061Al-Si Alloy in 0.1M HCl Medium
}

\author{
A. S. Fouda, ${ }^{1, *}$,F.I. El-Dossoki ${ }^{2}$, W.T.Elbehairy ${ }^{1}$, A.Elmohamady $^{1}$ \\ ${ }^{1}$ Department of Chemistry, Faculty of Science, El-Mansoura University, El-Mansoura-35516, Egypt, \\ ${ }^{2}$ Department of Chemistry, Faculty of Science, Port Said University, Egypt \\ *E-mail: asfouda@hotmail.com, asfouda@mans.edu.eg
}

doi: $10.20964 / 2018.11 .95$

Received: 9 July 2018 / Accepted: 11 September 2018 / Published: 1 October 2018

The inhibition performance of Flubendazole (FBZ) drug on the corrosion of the 6061Al-Si alloy in $0.1 \mathrm{M} \mathrm{HCl}$ has been observed by $\mathrm{AC}$ impedance (EIS), Tafel diagrams, electrochemical frequency modulation (EFM) and mass loss (ML) methods. The inhibition efficiency (IE) rises by raising the Flubendazole extent (FBZ) and diminished by raising the temperature. Polarization curves have shown that the Flubendazole acts as a mixed-kind inhibitor. FBZ adsorption on the alloy surface was obeying Temkin isotherm. Thermodynamic adsorption functions $\left(\Delta \mathrm{G}^{\circ}{ }_{\text {ads }}, \Delta \mathrm{H}^{\circ}\right.$ ads and $\Delta \mathrm{S}^{\circ}$ ads $)$ and the activation parameters $\left(\mathrm{E}_{\mathrm{a}}^{*}, \Delta H^{*}, \Delta S^{*}\right)$ were calculated and analyzed. Surface analysis using Scanning Electron Microscopy (SEM) has confirmed the existence of a protective film of drug molecules onto Al alloy surface. The surface analysis of Al alloy was performed by scanning electron microscope (SEM), AFM (atomic force microscopy) and (FT-IR) Fourier transform infrared spectra.

Keywords: Corrosion, Adsorption, Al alloy, HCl, SEM, AFM, FTIR

\section{$\underline{\text { FULL TEXT }}$}

(C) 2018 The Authors. Published by ESG (www.electrochemsci.org). This article is an open access article distributed under the terms and conditions of the Creative Commons Attribution license (http://creativecommons.org/licenses/by/4.0/). 